\title{
A Gestão de Recursos Humanos em hospitais do Sistema Único de Saúde (SUS) e sua relação ao modelo de assistência: um estudo em hospitais de Belo Horizonte, Minas Gerais
}

\author{
Marina Campos Morici \\ Centro Universitário de Belo Horizonte \\ Allan Claudius Queiroz Barbosa \\ Universidade Federal de Minas Gerais
}

\begin{abstract}
O artigo discute a gestão de recursos humanos em hospitais de Belo Horizonte, Minas Gerais, considerando a relevância do debate no contexto gerencial contemporâneo e suas implicações ao modelo assistencial preconizado pelos hospitais analisados. A partir de levantamento de dados (entrevistas semiestruturadas com gestores e profissionais de recursos humanos e análise de documentos pertinentes às práticas e normatizações existentes), o estudo aponta uma defasagem nas políticas e práticas de recursos humanos, com a contratação via concurso público não conseguindo suprir de forma ágil a atividade assistencial. Os resultados apontam ainda ser esse um fator determinante na fixação e motivação dos profissionais, o que diferencia em termos de autonomia aqueles hospitais onde a gestão de recursos humanos ocorre via regras do direito privado.
\end{abstract}

Palavras-chave: políticas e práticas de recursos humanos; hospitais; recursos humanos em saúde.

La Gestión de los Recursos Humanos en hospitales del Sistema Único de Salud y su relación con el modelo de asistencia: un estudio en hospitales de Belo Horizonte, Minas Gerais

El artículo discute la gestión de los recursos humanos en hospitales de Belo Horizonte, Minas Gerais, considerando la relevancia del debate en el contexto gerencial contemporáneo y sus implicaciones con el modelo asistencial preconizado por los hospitales analizados. A partir del inventario de datos (entrevistas semiestruturadas con los gestores y profesionales de recursos humanos y el análisis de documentos pertinentes a las prácticas y los reglamentos existentes), el estudio apunta para un desfasaje en las políticas y en las prácticas de recursos humanos, siendo que la contratación por vía de concurso público no logra suplir de forma ágil la actividad asistencial. Los resultados también señalan que éste es un factor determinante en la fijación y en la motivación de los profesionales, lo que diferencia en términos de autonomía a aquellos hospitales donde la gestión de recursos humanos ocurre por vía de reglas del derecho privado.

Palabras clave: políticas y prácticas de recursos humanos; hospitales; recursos humanos en la salud.

Artigo recebido em 7 fev. 2012 e aceito em 9 nov. 2012.

Rev. Adm. Pública - Rio de Janeiro 47(1):205-225, jan./fev. 2013 
Human Resource Management in hospitals and its relation to model assistance: a study of hospitals in Belo Horizonte, Minas Gerais

The article discusses human resource management in hospitals in Belo Horizonte, Minas Gerais. It considers the relevance of the debate within contemporary management and its implications for the healthcare model advocated by the hospitals under consideration. From the data collected (semistructured interviews with managers and human resource professionals and the analysis of relevant documents to existing rules and practices), the study indicates a lag in that the human resource policies and practices and hiring via tender cannot supply the needs of supportive activities sufficiently. The results also indicate that this is a determining factor in the setting and motivation of staff. This differs in terms of autonomy from those hospitals where human resource management is based on rules of private sector.

KEY WORDs: policies and practices of human resources; hospitals; health human resources.

\section{Introdução}

Este trabalho procura descrever e discutir as políticas e práticas de recursos humanos desenvolvidas em hospitais que atendem pelo Sistema Único de Saúde (SUS). Considerando sua interface com a assistência, visa também analisar a forma de administração (natureza pública ou privada) das instituições em termos de sua adoção ao modelo assistencial preconizado. A área da saúde se caracteriza por uma grande demanda de mão de obra qualificada, o que exige adoção de políticas e práticas de gestão de recursos humanos capazes de responder a esse contexto. Com a crescente necessidade em buscar novas configurações capazes de proporcionar uma gestão mais flexível, notadamente através de parcerias entre o ente público e uma organização de direito privado, a dimensão gerencial de recursos humanos assume uma relevância ímpar.

Neste quadro, a forma de contratação influencia a gestão de recursos humanos, na medida em que define, em última instância, a capacidade de decisão. Isso é corroborado por La Forgia e Couttolenc, que afirmam ser a capacidade de decisão a respeito dos funcionários um fator crucial para a gestão da organização hospitalar: "O atendimento hospitalar depende muito dos funcionários, a autoridade de decisão com respeito aos mesmos pode ser um fator crucial" (La Forgia e Couttolenc, 2009:215).

Isso permite uma construção teórica que inicialmente situa o debate sobre recursos humanos considerando ser esse um campo de grande complexidade conceitual e operacional/prática. Posteriormente, uma discussão sobre o SUS e a inserção dos hospitais permite o entendimento da lógica de recursos humanos. A metodologia do estudo bem como seus resultados e considerações finais encerram o debate proposto. 


\section{Referencial teórico}

O debate sobre recursos humanos em saúde necessariamente exige entender como é tratado esse tema tanto na acepção usual quanto na lógica do SUS. Com efeito, é sempre necessário resgatar a inserção histórica para entender seu papel "operacional" nas ações organizacionais e o que isso representa em termos de impacto. Voltada à administração de pessoal e a mecanismos assistenciais de suporte ao empregado, esta perspectiva, conforme observa Albuquerque (1987), permite observar a evolução do departamento de pessoal com as dificuldades inerentes à "importação" de um modelo gerencial norte-americano, notadamente na forma como foram estabelecidas as relações de trabalho no Brasil. A administração de recursos humanos nas organizações brasileiras, segundo Albuquerque (1987:11), "tem sua evolução marcada pelas limitações da legislação trabalhista, pela importação de técnicas de administração de pessoal de países desenvolvidos, pela ausência e manipulação no movimento sindical durante muitos anos e pela influência de variáveis ambientais, externas à organização". É comum observar na literatura sobre recursos humanos a tipologização em fases ou momentos marcados por características inerentes a um dado momento, conforme apregoa Sarsur (1999), ao definir fases nesta evolução: pré-jurídico-trabalhista (pré-1930), marcada pela inexistência da legislação trabalhista e de departamento pessoal; burocrática (1930 a 1950), com o surgimento do departamento pessoal para atender as exigências da legislação trabalhista elaborada nesse período; tecnicista (décadas de 1950 e 1960), preocupada com eficiência e produtividade em função da implantação da indústria automobilística; sistêmica (décadas de 1960 a 1970), com o surgimento da área de recursos humanos na estrutura organizacional; a década de 80, marcada pelo contexto de novas relações de trabalho, e a década de 90 , caracterizada pelo acentuado avanço tecnológico e o aumento da competitividade, trazendo um grande desafio à função de recursos humanos no que se refere a repensar sua posição e adotar novas práticas. Considerando os processos de recursos humanos e seu reforço ao componente histórico, uma visão considerada tradicional baseia-se na subdivisão de atividades afins correlacionadas a um mesmo objetivo. Ou seja, classicamente são consideradas cinco subáreas de caráter técnico: suprimento/provisão (recrutamento e seleção), aplicação (análise e descrições de cargos, plano de carreiras e avaliação de desempenho), manutenção (remuneração e benefícios, medicina e segurança do trabalho), desenvolvimento (treinamento e desenvolvimento) e controle (auditoria, banco de dados e sistema de informações) (Albuquerque, 1987).

Essa tipologia não sugere imobilismo ou independência, o que permite entender um dos grandes desafios à necessária integração dos processos, de forma que contribuam efetivamente para o alcance das estratégias organizacionais e consequente realização dos objetivos pessoais. Nesta perspectiva, Boxall e Purcell (2007) observam ser a gestão de recursos humanos um processo inevitável nas organizações, dedicado ao gerenciamento de pessoas e do trabalho executado, em diferentes níveis de gestão, e que tende à incorporação de diferentes estilos de gestão e matizes ideológicos.

O que, em última instância, se observa é que estes processos se desenvolvem pouco articulados às estratégias organizacionais, reforçando a observação de Fischer (1998:119) de que "o papel da gestão de RH é manter a competência instalada, evitando a depreciação deste 
ativo intelectual da organização". Mais recentemente, as transformações do éthos produtivo, com um discurso pautado pela lógica dos resultados e cumprimento de metas, tornaram evidente a dificuldade de ajuste da atividade de recursos humanos. À luz desse debate, a lógica da gestão de recursos humanos no contexto organizacional apresenta contradições quando confrontada com a realidade brasileira. Caldas e colaboradores (2003), por exemplo, demonstraram o expressivo crescimento na produção científica, mas indicaram uma preocupação fortemente centrada em estudos que não ampliam o horizonte analítico, restringindo-se, em sua imensa maioria, a uma análise de empresas ou situações com suas dadas especificidades.

Essa situação evidencia a ênfase comportamental dos artigos publicados, com provável ligação a um ambiente organizativo que remonta ao período de maior estabilidade, típico da chamada era de ouro do fordismo (pós-Segunda Guerra Mundial até a década de 1970) e uma abordagem metodológica que não permite generalizações confiáveis.

Este quadro evidencia um debate ainda secundário e com pouco destaque e voz diante das decisões de natureza estratégica das organizações. No caráter contemporâneo do debate, Kamoche (2001) observa que a discussão sobre recursos humanos teve algumas marcas significativas durante as décadas de 1980 e 1990, notadamente no que concerne aos temas em voga naquele período. Boxall, Purcell e Wright (2007), por sua vez, identificam três principais campos na gestão de recursos humanos: a micro gestão, que abrange as subfunções de recursos humanos (recrutamento, seleção, formação etc.) e o debate sobre as relações de trabalho em sentido mais amplo. A gestão estratégica de recursos humanos abrange as estratégias globais adotadas por unidade de negócio e empresas e procura mensurar o impacto sobre o desempenho. E, por fim, a gestão internacional de recursos humanos, que examina como as empresas operam além de suas fronteiras nacionais. Lengnick-Hall e colaboradores (2009) identificaram sete grandes temas na perspectiva temporal que alimentaram a trajetória do debate sobre estratégia de recursos humanos: contingência e ajuste; foco na gestão de pessoas para criação de contribuições estratégicas; elaboração de componentes do sistema de recursos humanos e da estrutura; ampliação do escopo do debate; a realização de implementação e execução; medição de resultados; e, por fim, avaliação das questões metodológicas. Cada um desses temas desempenhou um papel significativo na evolução do campo e proporcionou diferentes approaches ao debate. Deadrick e Gibson (2007) sugerem que há inúmeras lacunas que dissociam as duas dimensões, variando, em função da área, quanto à magnitude e profundidade.

Existem argumentações de que o campo de recursos humanos, em grande medida, não apresenta uma teoria para orientar a pesquisa sobre as principais questões (Campbell, 1990), sendo parte da pesquisa realizada nesta área de baixa qualidade e normalmente descrevendo fenômenos organizacionais, em detrimento da eficácia das práticas de recursos humanos (Dunnette, 1990).

À luz destas diferentes e múltiplas argumentações, existe um relativo entendimento de que a área de recursos humanos tem se caracterizado por uma postura mais passiva e adaptativa diante das transformações, fato observado por autores em estudos conduzidos na década de 1990 e reforçado com a entrada no século XXI. Isso demonstra a relevância do debate e sua relevância no espaço da saúde, que exige inicialmente a compreensão de sua lógica histórica em termos de constituição do SUS no Brasil. 


\subsection{0 sUS e os hospitais}

Em 1985, com o fim do regime militar, lideranças do movimento sanitário assumem efetivamente posições em postos-chave nas instituições responsáveis pela política de saúde no país. Na 8a Conferência Nacional de Saúde, em 1986, em Brasília, são lançados os princípios da Reforma Sanitária, aprovando-se a criação de um Sistema Único de Saúde, que se constituísse em um novo arcabouço institucional, com a separação total da saúde em relação à Previdência (Brasil, 2007).

Os principais desdobramentos da 8a Conferência Nacional de Saúde foram a constituição da Comissão Nacional de Reforma Sanitária (CNRS) e a conformação da Plenária Nacional de Saúde. A primeira foi responsável por elaborar a proposta do capítulo referente à saúde para a Constituição (Escorel e Teixeira, 2009).

A criação do SUS aconteceu com a promulgação da Constituição de 1988, redefinindo o conceito de saúde e incorporando novas dimensões em seu entendimento, tais como alimentação, moradia, emprego, lazer, educação etc.

O art. 197 da Constituição Federal (Brasil, 1988) define a relevância pública das ações e dos serviços de saúde, cabendo ao poder público dispor sobre sua regulamentação, fiscalização e controle. A celebração do SUS implica, portanto, a reafirmação destes três princípios somados à universalidade em todas as ações e serviços de saúde. Sua regulamentação por meio da Lei Federal nº 8.080/1990 veio acompanhada de resultados marcantes ao longo dos anos.

Com efeito, em 2006, a organização do SUS como uma rede diversificada envolvia cerca de 6 mil hospitais, 26 mil equipes de saúde da família, 215 mil agentes comunitários de saúde e 13 mil equipes de saúde bucal em mais de 5 mil municípios brasileiros (Brasil, 2006).

Nesse contexto, os hospitais integrantes do sistema enfrentam desafios como o subfinanciamento, a baixa capacidade gerencial e a ineficiência de escala. O subfinanciamento é um tema largamente discutido, e pode ser constatado mediante o pagamento insuficiente de alguns procedimentos, para os quais são pagos valores muito abaixo de seus custos. Além dos desafios financeiros, o sistema funciona com baixa capacidade gerencial. Na área de Recursos Humanos, a baixa capacidade gerencial está diretamente relacionada à dificuldade de monitoramento e avaliação dos resultados individuais e dos gastos com pessoal (Brasil, 2006).

O desafio da eficiência é destacado por La Forgia e Couttolenc (2009). Os autores afirmam que os hospitais podem avançar muito no que diz respeito à utilização dos recursos disponíveis no SUS e a eficiência pode ser aumentada a partir de investimentos em instituições de maior porte, uma vez que foi encontrado pelos autores sensível aumento na eficiência dos hospitais à medida que o número de leitos cresce.

Mesmo sendo sensíveis os avanços obtidos pelo SUS no campo da Atenção Primária (Brasil, 2009), ainda está presente nos hospitais a sobrecarga de atendimentos imposta pelos casos não atendidos na atenção básica. Lobato (2000) destaca que, muitas vezes, devido à falta de funcionamento pleno da atenção básica ou mesmo pela falta de uma estrutura mínima de operação, recai sobre os hospitais o peso das questões de saúde não resolvidas no nível primário. Os usuários tendem a procurar unidades de emergência em hospitais, o que 
sobrecarrega o atendimento nas mesmas. Com isso, problemas de saúde mais simples passam a competir com emergências reais de atenção. Essa questão onera duplamente a rede: por um lado, diminui a capacidade de atendimento hospitalar das reais demandas de média e alta complexidade e, por outro, onera financeiramente a máquina estatal, uma vez que procedimentos realizados em serviços especializados custarão mais aos cofres públicos.

Para Elias (1999), a discussão sobre modalidades de gestão transformou-se numa das questões centrais na agenda pública brasileira, destacando-se mais do que as discussões a respeito da assistência em si. Longo (2004) corrobora este aspecto ao situar que a maior motivação para a busca dessas formas alternativas de gestão está na possibilidade de flexibilização da Gestão de Recursos Humanos.

Os hospitais brasileiros estão submetidos a diferentes regimes administrativos e modelos de gestão. Braga Neto, Barbosa e Santos (2009) distinguem três grandes conjuntos de hospitais segundo propriedade de patrimônio e normas administrativas de funcionamento. $\mathrm{O}$ primeiro seria o de caráter público e estatal, integrando a administração pública. O segundo é constituído no âmbito privado, mas compõe de forma diferenciada interesses de caráter público, e o terceiro é composto do âmbito privado, operado com base nas regras de mercado, podendo ou não prestar serviço para o SUS.

\subsection{A gestão de recursos humanos e a saúde}

O Relatório da Organização Mundial da Saúde (OMS) (2007) ressalta a importância dos recursos humanos nos sistemas de saúde. No caso brasileiro, isso ocorre e vem se difundindo a partir da percepção de gestores, trabalhadores e representantes do governo de que a formação, o desempenho e a gestão de recursos humanos afetam profundamente a qualidade dos serviços prestados e o grau de satisfação dos usuários (Seixas, 2002).

Para Fonseca e Seixas (2002), as políticas de recursos humanos são destacadas como prioritárias para a consecução de um SUS democrático, equitativo e eficiente. As dimensões do ideário do SUS influenciam fortemente a formulação de políticas de recursos humanos para a saúde no Brasil, levando-se em conta as questões conceituais (definição de saúde na Constituição Federal), as diretrizes (universalidade, integralidade e equidade) e a organização do sistema (pluralista, regionalizado, hierarquizado e descentralizado, com direção única em cada esfera de governo).

Os desafios de recursos humanos encontrados no sistema de saúde refletem-se nas instituições que compõem a rede. Cada instituição, no entanto, responde a esses desafios de maneira própria, de acordo com sua organização interna e a capacidade de estruturação.

A superação dos desafios relativos às questões de recursos humanos na área da saúde internacional é abordada por diversos autores. Podem ser resumidas, segundo Pierantoni, Varella e França (2004), em quatro grandes objetivos: aumentar a cobertura e a fixação das equipes de profissionais, objetivando assegurar a prestação de serviços de saúde de forma adequada e equitativa; garantir competências e habilidades-chave para a força de trabalho 
em saúde; aumentar o desempenho da equipe de profissionais diante de objetivos definidos; e fortalecer a capacidade de planejamento e gerenciamento de RH no setor saúde.

Os mesmos objetivos podem ser encontrados no relatório da Organização Mundial de Saúde. São apontadas estratégias de recursos humanos para lidar com os problemas mundiais de saúde. Institucionalmente, as estratégias relativas à força de trabalho devem focar três desafios principais: melhorar o recrutamento, ajudar a força de trabalho a melhorar seu desempenho e diminuir a rotatividade dos trabalhadores. A otimização do desempenho dos atuais trabalhadores adquire ênfase porque: a) provavelmente apresenta resultados mais rápidos do que o aumento do número de trabalhadores; b) as possibilidades de aumento do número de trabalhadores são limitadas na maioria dos casos; c) a força de trabalho com bom desempenho auxilia o recrutamento de novos trabalhadores, bem como a conservação dos existentes; e d) os governos devem assegurar a justiça e a eficiência da utilização dos recursos financeiros disponíveis (OMS, 2007).

Seria função de recursos humanos nas organizações hospitalares a gestão do emprego, de sistemas de apoio necessários para a realização do trabalho e a criação de um ambiente de trabalho positivo, considerando as três etapas apontadas pela OMS (2007): a entrada de funcionários, a implementação das alavancas para melhoria do desempenho dos trabalhadores e a gestão da saída de profissionais.

\section{Procedimentos metodológicos}

\subsection{0 desenho do estudo}

A metodologia qualitativa foi escolhida no presente estudo, entendendo-se tratar da melhor forma de buscar a compreensão das relações estabelecidas entre as políticas e práticas de Recursos Humanos presentes em hospitais no SUS, a capacidade de resposta dessas políticas e práticas de Recursos Humanos às demandas de assistência hospitalar e as possíveis diferenças entre políticas e práticas de Recursos Humanos desenvolvidas em hospitais com diferentes naturezas jurídicas.

O estudo se caracteriza como descritivo. Segundo Seltiz e colaboradores (1965), estes estudos podem ser usados com a intenção de descobrir ou testar se determinadas variáveis estão associadas. Em um primeiro momento, foram executadas as atividades de descrição dos fenômenos e a relação entre as variáveis estudadas em cada uma das organizações hospitalares. No segundo momento da pesquisa buscou-se estabelecer relações entre as realidades presentes em cada uma das organizações e, posteriormente, entre as características peculiares a cada um dos grupos de hospitais estruturados.

Visando estruturar a coleta de dados dentro do esboçado teoricamente, a definição de categorias de análise mostrou-se essencial para alcançar os objetivos específicos previamente estabelecidos no presente estudo. O quadro 1 identifica as categorias escolhidas. 


\section{Quadro 1 \\ Categorias de análise}

Categoria de análise
Políticas e práticas de Recursos Humanos (para gestão da entra-
da, do desempenho e da saída de pessoal) nos hospitais.
Contribuições e/ou entraves provenientes da forma de organi-
zação da gestão de pessoal para a assistência.
Contribuições e/ou entraves provenientes da forma de admi-
nistração das instituições hospitalares.

nistração das instituições hospitalares.

\section{Justificativa da escolha}

Investigar de que forma as políticas e práticas de Recursos Humanos estão estruturadas em instituiç̃ões hospitalares inseridas no SUS.

Estabelecer as relações existentes entre as políticas e práticas de Recursos Humanos e as atividades assistenciais, delimitando as contribuições e/ou os entraves provenientes da forma de organização da gestão de pessoal.

Delimitar as diferenças entre as contribuições e/ou entraves das políticas e práticas de Recursos Humanos na assistência em hospitais administrados por instituições de diferentes naturezas jurídicas.

Fonte: Elaborado pelos autores.

As categorias de análise foram divididas em dimensões. As dimensões, por sua vez, deram origem às subcategorias de análise. O quadro 2 apresenta esse detalhamento e a origem dos dados de cada uma delas.

Quadro 2

\section{Categorias de análise e seu desdobramento em dimensões}

\begin{tabular}{|c|c|c|}
\hline Categorias de análise & Dimensões & Dados a serem colhidos \\
\hline \multirow{13}{*}{$\begin{array}{l}\text { Políticas e práticas de } \\
\text { Recursos Humanos }\end{array}$} & Entrada & Processo de recrutamento \\
\hline & & Processo de seleção \\
\hline & \multirow[t]{4}{*}{ Desempenho (emprego) } & Existência de descrição de postos de trabalho \\
\hline & & Existência, clareza e divulgação de normas e códigos de conduta \\
\hline & & Gestão de habilidades combinadas às tarefas \\
\hline & & Supervisão \\
\hline & \multirow{3}{*}{$\begin{array}{l}\text { Desempenho (sistema } \\
\text { de apoio) }\end{array}$} & Remuneração em relação ao mercado (percepção dos gestores) \\
\hline & & Canais formais e informais de comunicação \\
\hline & & Infraestrutura e suprimentos gerais do hospital \\
\hline & \multirow{3}{*}{$\begin{array}{c}\text { Desempenho (ambiente } \\
\text { favorável) }\end{array}$} & Aprendizado contínuo (programas e práticas) \\
\hline & & Gestão de equipes \\
\hline & & Responsabilidade com responsabilização \\
\hline & Saída & Gestão da rotatividade \\
\hline
\end{tabular}




\begin{tabular}{|ccc|}
\hline Categorias de análise & Dimensões & Dados a serem colhidos \\
\hline $\begin{array}{c}\text { Relação de políticas e } \\
\text { práticas de Recursos } \\
\text { Humanos com a } \\
\text { assistência }\end{array}$ & $\begin{array}{c}\text { Percepção dos gestores } \\
\text { de RH da relação } \\
\text { da assistência sobre a } \\
\text { relação }\end{array}$ & Percepção dos gestores de RH da relação \\
& $\begin{array}{c}\text { Forma de vinculação } \\
\text { Formas de vinculação de } \\
\text { pessoal }\end{array}$ & Predominante no hospital dos gestores da assistência sobre a relação \\
& Existência de gestão diferenciada dos diversos grupos de vinculação \\
\end{tabular}

Fonte: Elaborado pelos autores.

Isso permitiu a construção dos roteiros utilizados nas entrevistas (tanto dos gestores de RH quanto dos gestores assistenciais). As categorias refletem o referencial teórico adotado, tanto nas dimensões jurídico-normativas quanto naquelas associadas a Recursos Humanos especificamente e à área hospitalar.

\subsection{Os hospitais estudados: percurso de escolha}

Considerando a demarcação metodológica adotada e o espaço hospitalar como local de coleta de dados e aprofundamento das dimensões construídas no referencial teórico, a escolha dos casos a serem estudados, isto é, dos hospitais que atendem ao SUS se deu de forma intencional, procurando identificar aqueles com práticas e políticas de Recursos Humanos bem estruturadas e reconhecidas e claramente associadas ao modelo de assistência.

A delimitação territorial foi a cidade de Belo Horizonte, que conta com uma rede de saúde articulada, onde existem esforços integrados para que as ações de saúde potencializem o cuidado aos pacientes. Desde a década de 1990 a Secretaria Municipal já havia assumido toda a gestão dos serviços de saúde no seu território (Magalhães Júnior, 2010).

Segundo Magalhães Júnior (2010), a experiência de estruturação da rede de saúde de Belo Horizonte é reconhecida por diversos estudos científicos como a maior e mais densa experiência moderna brasileira de atenção primária com base em todo o sistema municipal de saúde. A organização do sistema municipal de saúde passou ao longo dos últimos anos pela reorganização da atenção primária, das redes de suporte e por ações articuladas de saúde coletiva.

O município de Belo Horizonte conta, desde o advento da gestão plena em 1994, com uma série de instrumentos para gestão do sistema municipal de saúde, regulando todos os serviços públicos e privados contratados pelo SUS. Com isso, foi possível a reorganização do sistema, com desenvolvimento de controles e avaliações objetivando a coibição de fraudes, 
o redimensionamento de recursos do teto financeiro municipal de um setor para o outro, o investimento vigoroso na rede própria de serviços, o investimento em tecnologias e a implantação de novas modalidades assistenciais e a participação da população na gestão do sistema (Magalhães Júnior, 2010).

O alto grau de desenvolvimento da rede de saúde municipal torna-se um atrativo para a realização do estudo no município de Belo Horizonte. No que diz respeito às instituições hospitalares, o município conta com o total de 89 hospitais (públicos e privados), sendo 37 hospitais gerais, 39 hospitais especializados, um pronto-socorro geral e dois especializados, segundo dados do CNES (2011).

Os hospitais inicialmente escolhidos para participar do estudo foram definidos após consulta prévia à Subsecretária de Saúde do Município sobre a viabilidade de acesso às informações pertinentes ao estudo, sendo identificado um grupo inicial de cinco hospitais. Os mesmos foram convidados a participar do estudo e quatro responderam afirmativamente. Entre os que aceitaram participar, foi possível identificar aqueles hospitais administrados segundo as regras do direito público (uma autarquia federal e uma autarquia municipal) e aqueles hospitais administrados segundo as regras do direito privado (uma fundação privada e um contrato de gestão entre o estado de Minas Gerais e uma fundação privada), sendo dois hospitais em cada uma dessas tipologias.

O hospital $\mathrm{HBH}^{1}{ }^{1}$ é uma autarquia da prefeitura municipal de Belo Horizonte. Possuía 413 leitos no momento do estudo. Compreende, além de um hospital geral, um pronto-socorro de urgência e emergência. O hospital HBH2 faz parte de uma instituição federal de ensino superior e possui 433 leitos. É um hospital de ensino voltado para o desenvolvimento de tratamentos inovadores e complexos. No momento da coleta de dados, atendia o SUS e alguns convênios de saúde. O hospital HBH3 é uma instituição filantrópica particular. Trata-se de hospital geral com 233 leitos. No momento da coleta de dados, 90\% de seus atendimentos eram pelo SUS. O hospital HBH4 é fruto de uma parceria "público-público" entre a Secretaria de Saúde do Estado de Minas Gerais e uma universidade pública de âmbito federal. O hospital possuía no momento da pesquisa 319 leitos voltados para o atendimento de urgência e emergência, traumatológica e não traumatológica.

\subsection{Coleta de dados: fontes e instrumentos}

A metodologia de coleta de dados visou atuar de maneira a possibilitar o entendimento da estrutura de funcionamento da área de Recursos Humanos inserida na lógica da gestão de cada hospital estudado, bem como sua relação com as atividades assistenciais.

\footnotetext{
${ }^{1}$ Foi adotada esta terminologia para preservar o sigilo acerca dos hospitais estudados, denominados HBH1 a $\mathrm{HBH} 4$.
} 
Os estudos de caso foram realizados mantendo-se os mesmos critérios em todas as instituições selecionadas, sendo colhidos dados através de: entrevistas, observação direta e análise de documentos institucionais e normativos (legislação) disponibilizados. A utilização de diferentes fontes de dados pretende aumentar a confiabilidade das informações colhidas, uma vez que permite a confrontação de dados contrastantes. Com a intenção de colher informações e percepções tanto de profissionais ligados ao setor de Recursos Humanos quanto da área da assistência, as entrevistas foram realizadas em todos os casos com representantes dos dois grupos: profissionais de Recursos Humanos e gestores assistenciais.

Na área de Recursos Humanos, foi priorizada a coleta de dados junto ao responsável geral, e a entrevista a analistas e/ou outros profissionais da área teve como objetivo complementar as informações recebidas. Foram colhidos dados a respeito das políticas e práticas de Recursos Humanos, buscando informações sobre a estruturação formal de políticas bem como das ações de gerenciamento de pessoal correntes na organização. Também foi investigada a percepção da relação das políticas e práticas de Recursos Humanos com as atividades assistenciais.

A entrevista com os gestores das áreas assistenciais tiveram como base um roteiro similar, enfocando as mesmas questões de Gestão de Recursos Humanos. Foram também colhidos dados a respeito da percepção destes gestores acerca da adequação das práticas e políticas de Recursos Humanos desenvolvidas para as necessidades diárias da assistência, explorando-se as contribuições ou os entraves causados pelas políticas e práticas tal como estruturadas. Para tanto, foram entrevistados responsáveis pela gestão de trabalhadores na área assistencial, dando-se especial ênfase a gestores das áreas de médicos e enfermagem, por se tratar do maior contingente de trabalhadores na área hospitalar.

Além das entrevistas, a observação direta tornou-se um importante método de coleta de dados, na medida em que, segundo Seltiz e colaboradores (1965), possibilita o registro do comportamento na ocasião em que ele ocorre. Esse registro direto dos acontecimentos pode ser utilizado em certas situações como forma de verificação das informações colhidas nas entrevistas.

A análise de documentos pertencentes às organizações estudadas completou a coleta de dados. Documentos impressos e informações disponibilizadas através de veículos institucionais são fontes ricas de dados a respeito de características organizacionais, desde que considerados os possíveis vieses presentes nos registros produzidos por cada um dos hospitais (Yin, 2005).

\subsection{Análise de dados}

O tratamento dos dados foi realizado tomando-se por base as categorias de análise descritas. Para tanto, utilizou-se o software NVivo9, em que foram compilados as transcrições de cada uma das entrevistas, os documentos disponibilizados pelas instituições e as observações de 
campo. O software foi utilizado em todas as etapas da análise, possibilitando a estruturação de cada um dos estudos de caso, bem como a comparação entre as instituições.

Na primeira etapa, o estudo de caso de cada um dos hospitais pesquisados foi realizado, buscando compreender a relação das políticas e práticas de Recursos Humanos com a atividade assistencial em cada uma das realidades institucionais.

Em um segundo momento, os estudos de caso resultantes da primeira fase foram divididos em dois grupos, segundo a forma de administração das instituições, contendo, portanto, cada grupo dois hospitais. Dentro desses grupos, os hospitais foram comparados entre si, com o objetivo de delimitar características de interação entre políticas e práticas de Recursos Humanos e o trabalho assistencial similares e relacionados à forma de gestão das organizações.

Posteriormente, foram comparadas a estruturação das políticas e práticas de Recursos Humanos e sua relação com a assistência nos dois grupos de hospitais (administrados segundo regras da administração pública e segundo regras da administração privada).

\section{Resultados encontrados}

A apresentação dos resultados encontrados está organizada segundo as categorias de análise previamente definidas no presente trabalho. Um dos objetivos deste estudo é a comparação entre a estruturação das políticas e práticas de Recursos Humanos em hospitais administrados segundo as regras públicas e segundo as regras privadas. Essa comparação tem por objetivo o entendimento de como essas políticas e práticas são influenciadas pela forma de contratação dos hospitais. Para tanto, serão seguidas as dimensões de análise previamente definidas. $\mathrm{O}$ quadro 3 sintetiza os resultados encontrados nos hospitais.

Estes resultados, embora amplos, permitem destacar, por exemplo, a forma de vinculação e, em última instância, o modelo de recrutamento e seleção adotado. Os hospitais administrados segundo as regras públicas vinculam seus funcionários por meio do RJU e aqueles administrados pelas regras privadas vinculam os trabalhadores segundo as regras da CLT. O ingresso nos hospitais orientados pelas regras públicas ainda é prejudicado pela falta de concursos regulares e pela morosidade desse processo seletivo. Com isso, torna-se indispensável ao funcionamento do hospital a contratação de profissionais subordinados a outros vínculos de trabalho, mais imediatos e flexíveis. Nos hospitais administrados pelas regras privadas, a contratação acontece via CLT. Vale ressaltar, no entanto, que a contratação dos profissionais médicos não passa por esse fluxo, sendo selecionados por mecanismos informais nas duas instituições.

A remuneração é diferente nos dois grupos estudados. Nos hospitais administrados segundo as regras públicas os salários estão definidos em tabela negociada com o sindicato ou por lei específica, e nos hospitais administrados segundo as regras privadas eles são definidos de acordo com o mercado. 


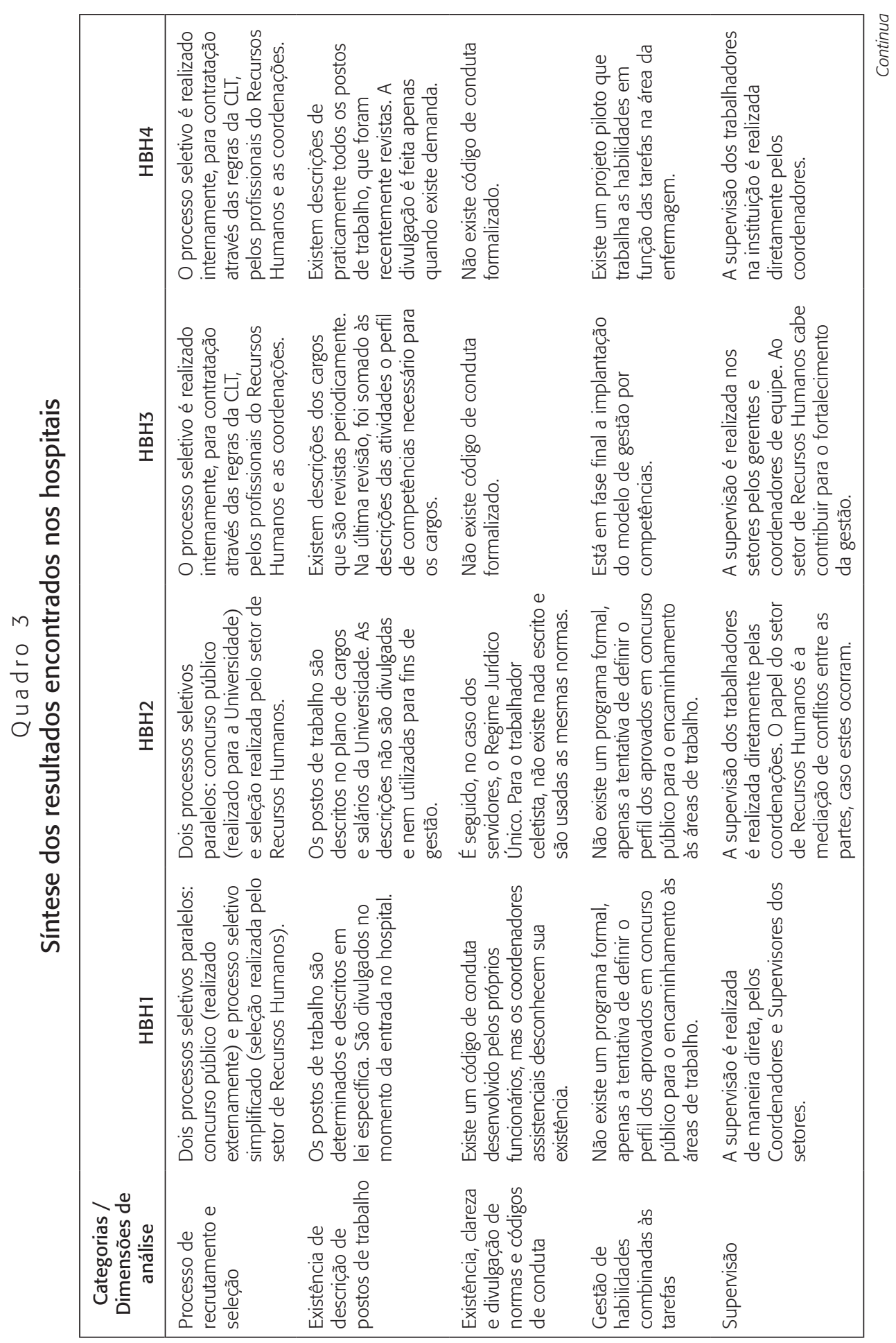




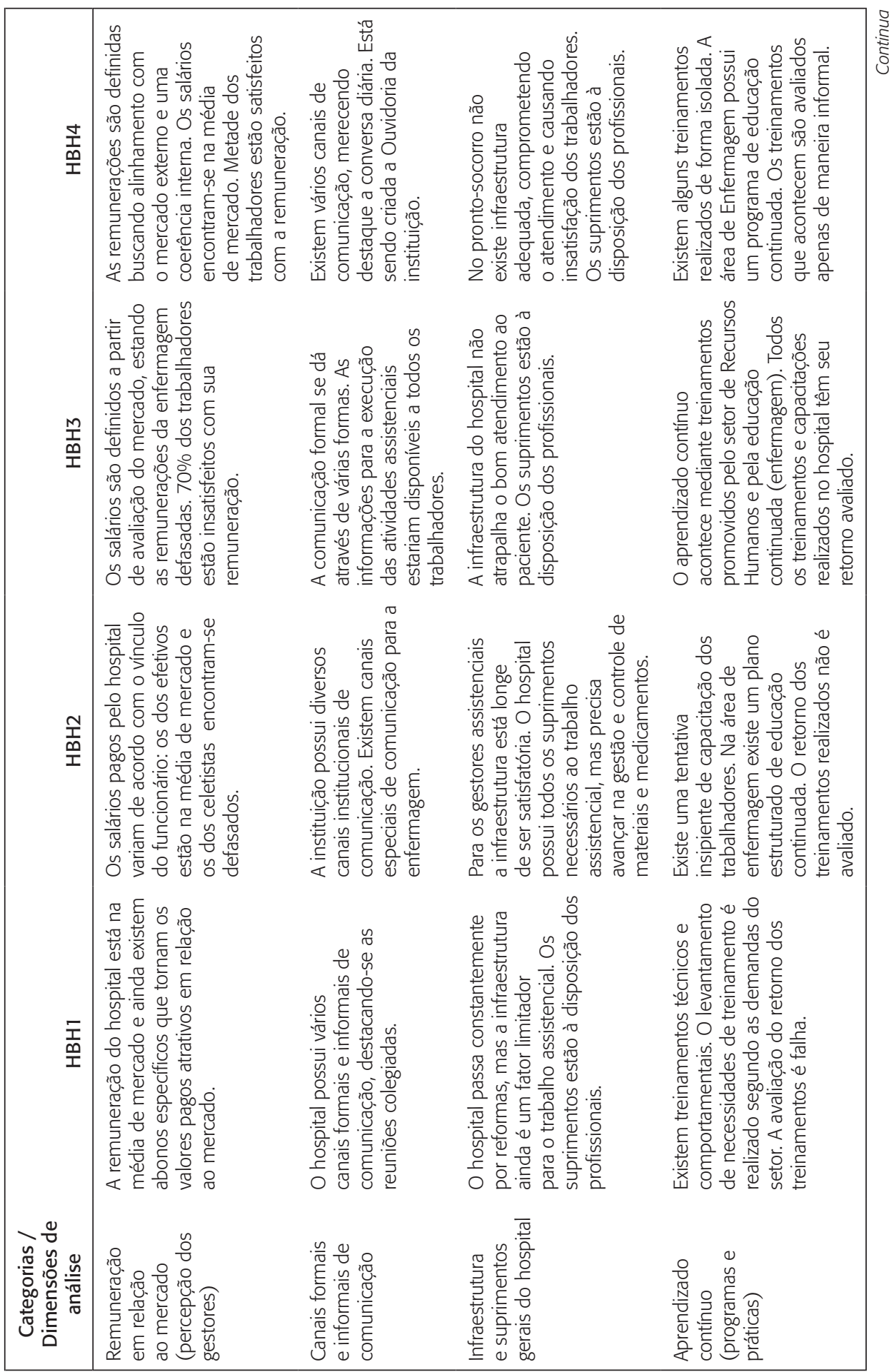

Rev. Adm. Pública - Rio de Janeiro 47(1):205-225, jan./fev. 2013 


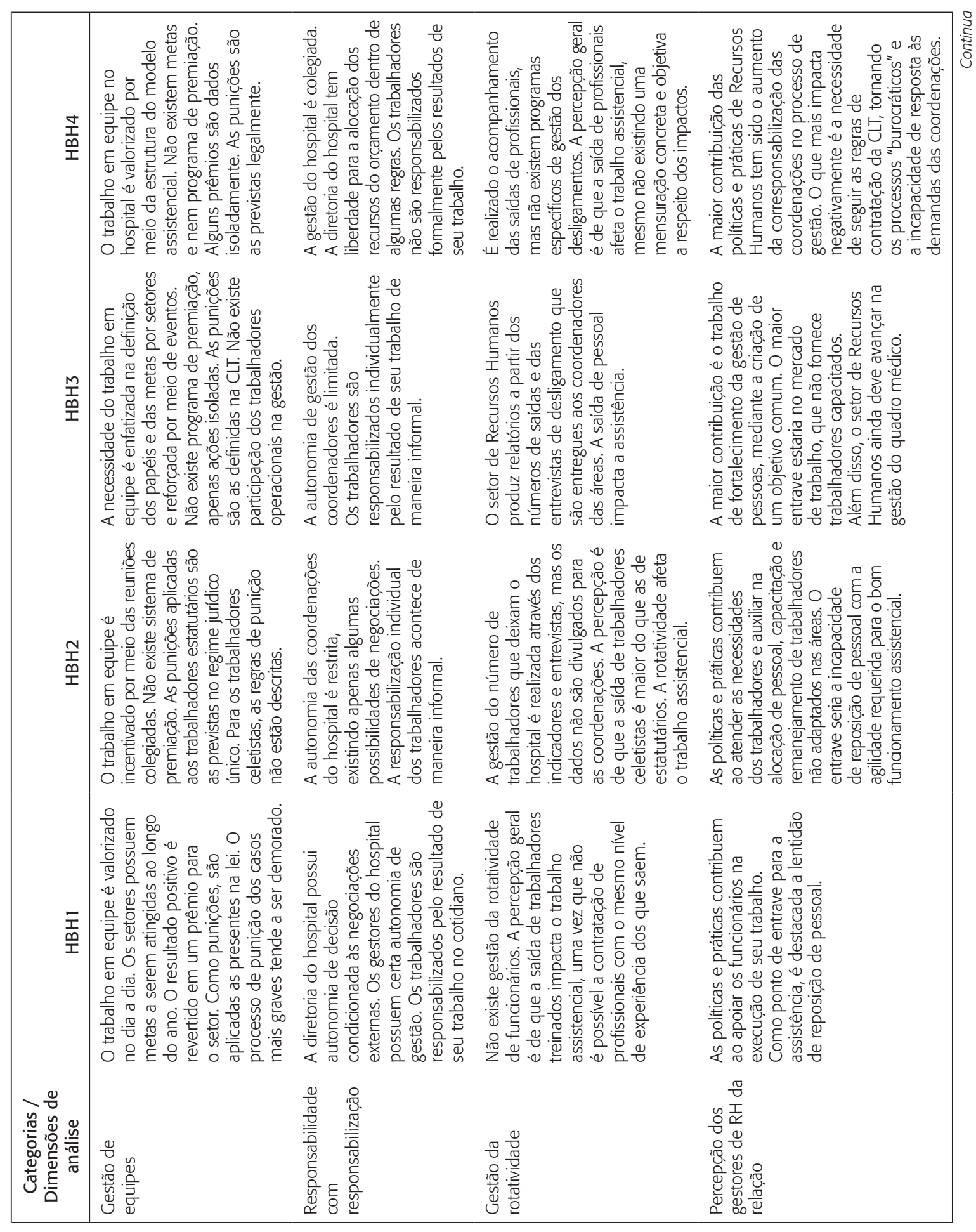

Rev. Adm. Pública - Rio de Janeiro 47(1):205-225, jan./fev. 2013 


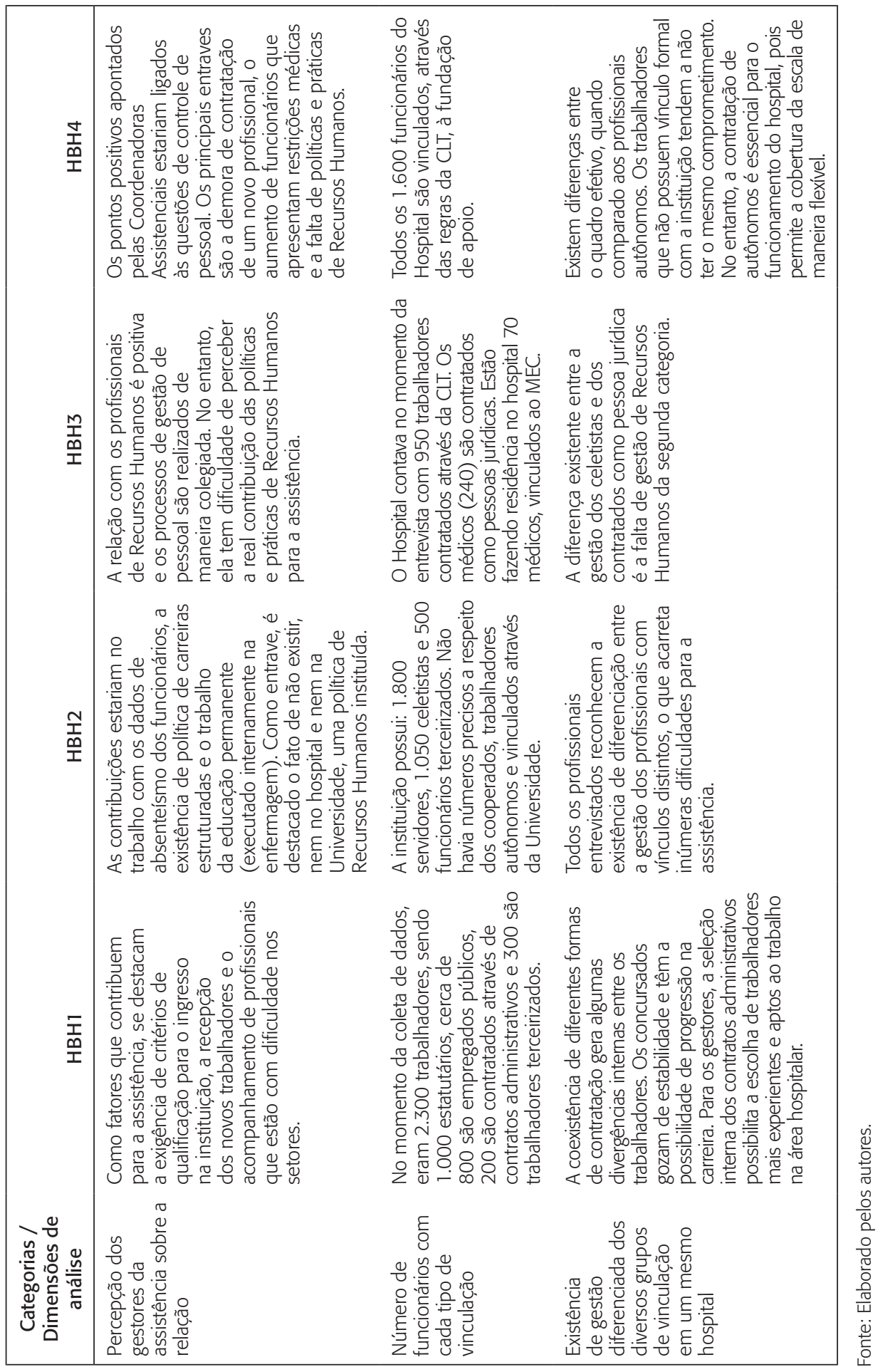

Rev. Adm. Pública - Rio de Janeiro 47(1):205-225, jan./fev. 2013 
As carreiras nos hospitais administrados segundo as regras públicas oferecem a seus trabalhadores planos bem definidos e progressões baseadas em tempo de serviço e avaliações de desempenho. Nos hospitais administrados segundo as regras privadas não existe definição formal de carreira e os aumentos salariais são concedidos de forma isolada ou como resultado de negociação sindical.

A avaliação de desempenho, por ser um critério para a progressão na carreira, é aplicada nos hospitais administrados segundo as regras públicas de forma generalizada. Nos hospitais administrados segundo as regras privadas, mesmo que não totalmente implantadas, as avaliações de desempenho são vistas como importantes para o desenvolvimento do quadro de funcionários.

De forma geral, nos hospitais administrados segundo as regras públicas, a política de recursos humanos tem um caráter de proteção aos trabalhadores, enquanto nos hospitais administrados segundo as regras privadas, a intenção é um posicionamento estratégico em relação à gestão do hospital.

\section{Considerações finais}

Considerando o primeiro objetivo do trabalho, de investigar a capacidade das políticas e práticas de Recursos Humanos desenvolvidas em hospitais no SUS de darem respaldo às atividades assistenciais, foi possível constatar que existe uma grande defasagem do desenvolvimento destas políticas e práticas nas instituições, de maneira generalizada. Vários processos de Gestão de Recursos Humanos carecem de definições e implantação, como os sistemas de premiação. Na única instituição em que os mesmos existem, estão desconectados do desempenho individual.

A falta de estabelecimento das políticas e práticas de Recursos Humanos também é percebida pelos gestores assistenciais dos hospitais estudados. Os gestores relacionam vários problemas enfrentados pelas instituições no que dizem respeito à gestão de pessoal com a falta de definições internas e programas desenvolvidos. No entanto, como ponto positivo, há de se destacar a abertura desses profissionais para que essas políticas e práticas sejam desenvolvidas e o reconhecimento global de que esse trabalho tem grande potencial de contribuir para a assistência ao paciente.

Visando traçar uma possível diferenciação entre a forma de estruturação das práticas e políticas de Recursos Humanos em instituições hospitalares de diferentes naturezas jurídicas, o primeiro ponto essencial seria a confirmação de que a estruturação das políticas e práticas de Recursos Humanos nas instituições está de fato intimamente ligada à forma de contratação de pessoal adotada nos hospitais. As regras de contratação definem a base da estrutura de Recursos Humanos, sob os quais as demais políticas e práticas são alicerçadas. Nos hospitais estudados, as principais formas de contratação são o RJU (nas instituições geridas segundo as regras públicas) e por meio da CLT (instituições geridas segundo as regras privadas).

Uma vez analisadas as diferenças entre a estruturação das políticas e práticas de Recursos Humanos nas instituições de diferentes naturezas jurídicas, três outras questões podem ser depreendidas do estudo realizado. 
A primeira questão está relacionada com a estruturação do processo seletivo nas instituições e com a capacidade do mesmo de dar respaldo às atividades assistenciais. Seguindo o RJU, o ingresso nas instituições administradas segundo as regras públicas se dá prioritariamente através de concursos públicos. Esse processo seletivo claramente não é capaz de suprir a assistência com profissionais capacitados com a agilidade necessária, uma vez que os concursos não são realizados regularmente e, quando realizados, são processos morosos, compostos de várias etapas. Além da demora na provisão de pessoal, os critérios de seleção utilizados são questionados, por basearem-se nos títulos que os candidatos possuem e no conhecimento teórico, não existindo garantias de que esse conhecimento será refletido na prática do cuidado com o paciente.

Nas instituições administradas segundo as regras públicas, a falta de provisão de profissionais aprovados em concurso faz com que seja necessária a contratação de trabalhadores por meio de outros vínculos mais flexíveis, garantindo assim o número adequado de profissionais para o atendimento assistencial. Essa contratação contraria as leis vigentes, mas é vista como única alternativa para o pleno funcionamento das instituições de saúde pesquisadas.

Conclui-se, então, que a tentativa de garantir o ingresso justo de profissionais mediante a realização de concursos públicos, por sua própria ineficiência, gera uma situação paralela de contratação irregular.

No que diz respeito à agilidade de contratação e à possibilidade de seleção dos profissionais segundo o perfil necessário ao trabalho assistencial, a contratação pela CLT apresenta vantagens. Para os contratos pela CLT são desenvolvidos processos seletivos internos segundo as necessidades específicas das instituições, que podem ser realizados em prazos menores quando comparados aos concursos públicos.

No entanto, por serem próprios das instituições, não existem regras globais para esses processos seletivos. Normalmente, as vagas disponíveis só são divulgadas quando não existem interessados em número suficiente pela oportunidade, demonstrando a falta de publicidade dos processos de contratação. Mesmo sendo verificada preocupação dos profissionais das áreas de Recursos Humanos dos hospitais com a transparência na condução das seleções de pessoal, não existem garantias reais de isenção.

A segunda questão diferencial entre a estruturação das políticas e práticas de Recursos Humanos nas instituições com relação aos vínculos de trabalho emerge após a contratação dos mesmos. Convivem nas instituições trabalhadores com diferentes vínculos de trabalho e, consequentemente, com diferentes salários, benefícios, direitos etc. Essas diferenças influenciam na fixação e na motivação dos profissionais.

A fixação de profissionais mostrou ser um grande desafio em todas as instituições, principalmente pelo grande impacto causado na assistência pela perda de trabalhadores experientes, treinados e habituados às rotinas das instituições. A fixação se relaciona diretamente com a forma de contratação do profissional, e quanto mais estável seu vínculo de trabalho, mais ele tende a se fixar na instituição.

No entanto, os profissionais que possuem vínculos muito estáveis tendem a ser menos motivados com relação ao trabalho. Aparentemente, a complexidade dos processos de exoneração no serviço público gera nos empregados e funcionários públicos uma sensação de impunida- 
de quanto aos desempenhos insatisfatórios e uma consequente acomodação. Por outro lado, os trabalhadores contratados segundo as regras da CLT sentem que devem desempenhar bem suas funções, uma vez que, caso contrário, podem ser demitidos. No entanto, contratos muitos precários, como os estabelecidos com profissionais autônomos, também são incapazes de motivar os trabalhadores, que encaram a prestação de serviço como eventual e temporária.

Pode-se concluir que cada forma de vinculação tem vantagens e desvantagens em relação às demais. No entanto, ao levarmos em conta a premissa de que o desempenho do sistema de saúde depende do desempenho dos trabalhadores (OMS, 2007), é de se constatar que a questão da motivação e dedicação dos trabalhadores às atividades assistenciais é essencial para o bom atendimento ao usuário do SUS e, portanto, a contratação através da CLT seria vantajosa neste sentido.

A administração dos hospitais segundo as regras privadas (contratação via CLT), assim como definido por Braga Neto, Barbosa e Santos (2009), realmente garante ainda às instituições maior autonomia de gestão de seu pessoal, sendo essa a terceira questão a ser ressaltada.

Nos hospitais administrados segundo as regras do direito público, a capacidade de gestão do quadro de pessoal é limitada. A começar pela falta de autonomia na definição dos selecionados para o trabalho na instituição, o setor de Recursos Humanos não tem liberdade de negociação de salários e planos de carreira, de mudança de cargos ou de contar com o desligamento de trabalhadores inaptos de forma ágil. Com isso, cabe ao setor atividades cotidianas menos estratégicas para a instituição, tais como a assistência aos funcionários e o apaziguamento de conflitos.

Já nos hospitais administrados segundo as regras do direito privado, pode ser constatada uma tentativa de posicionamento estratégico das atividades de Recursos Humanos. Nessas instituições, a função principal do setor seria o fortalecimento da capacidade de gestão dos coordenadores em busca dos objetivos institucionais. No entanto, é de se destacar que o potencial de uma administração mais autônoma e flexível, baseada nas regras da CLT, não é explorado ao máximo nas instituições que se utilizam dessa forma de contratação prioritariamente. Assim como destacado inicialmente, muito ainda pode ser desenvolvido nesses hospitais em termos de gestão de pessoal.

\section{Referências}

ALBUQUERQUE, Lindolfo G. O papel estratégico de Recursos Humanos. Tese (livre-docência) — Faculdade de Economia, Administração e Contabilidade, Universidade de São Paulo, São Paulo, 1987.

BOXALL, Peter; PURCELL, John. Strategy and human resource management. 2. ed. Nova York: Palgrave MacMillan, 2007.

BOXALL, Peter; PURCELL, John; WRIGHT, Patrick. Human resource management: scope, analysis and significance. In: BOXALL, Peter; PURCELL, John; WRIGHT, Patrick. (Ed.). The Oxford handbook of human resource management. Oxford: Oxford University Press, 2007. p. 1-16. 
BRAGA NETO, Francisco C.; BARBOSA, Pedro R.; SANTOS, Isabela S. Atenção hospitalar: evolução histórica e tendências. In: GIOVANELLA, Ligia et al. (Org.). Políticas e sistemas de saúde no Brasil. Rio de Janeiro: Editora Fiocruz, 2009. p. 665-704.

BRASIL. Conselho Nacional de Secretários de Saúde. Assistência de média e alta complexidade no SUS. Brasília: Conass, 2007.

BRASIL. Conselho Nacional de Secretários de Saúde. Conass, SUS 20 anos. Brasília: Conass, 2009.

BRASIL. Conselho Nacional de Secretários de Saúde. Conass, SUS: avanços e desafios. Brasília: Conass, 2006.

BRASIL. Constituição da República Federativa do Brasil. 1988. Disponível em: <www.senado.gov. br/sf/legislacao/const>. Acesso em: 25 mar. 2011.

CALDAS, Miguel P. et al. Produção acadêmica em recursos humanos no Brasil: 1991-2000. Revista de Administração de Empresas, São Paulo, v. 43, n. 1, p. 105-122, jan./fev./mar. 2003.

CAMPBELL, John P. The role of theory in industrial and organizational psychology. In: DUNNETTE, Marvin D.; HOUGH, Leaetta M. (Ed.). Handbook of industrial and organizational psychology. Palo Alto: Consulting Psychologists Press, 1990. p. 39-73.

CNES. Cadastro Nacional de Estabelecimentos em Saúde. Disponibiliza informações das atuais condições de infraestrutura de funcionamento dos estabelecimentos de saúde em todas as esferas. Disponível em: <http://cnes.datasus.gov.br/Index.asp?home=1> Acesso em: 21 mar. 2011.

DEADRICK, Diana L.; GIBSON, Pamela A. An examination of the research-practice gap in HR: comparing topics of interest to HR academics and HR professionals. Human Resource Management Review, v. 17, n. 2, p. 131-39, jun. 2007.

DUNNETTE, Marvin D. Blending the science and practice of industrial and organizational psychology: where are we and where are we going? In: DUNNETTE, Marvin D.; HOUGH, Leaetta M. (Ed.). Handbook of industrial and organizational psychology. Palo Alto: Consulting Psychologists Press, 1990. p. 1-27.

ELIAS, Paulo E. PAS: um perfil neoliberal de gestão de sistema de saúde. Estudos Avançados, v. 13, n. 35 , p. $125-137,1999$.

ESCOREL, Sarah; TEIXEIRA, Luiz A. História das políticas de saúde no Brasil de 1822 a 1963: do Império ao desenvolvimento populista. In: GIOVANELLA, L. et al. (Org.). Políticas e sistemas de saúde no Brasil. Rio de Janeiro: Editora Fiocruz, 2009. p. 333-384.

FISCHER, André L. A constituição do modelo competitivo de gestão de pessoas no Brasil: um estudo sobre as empresas consideradas exemplares. Tese (doutorado em administração) — Faculdade de Economia, Administração e Contabilidade, Universidade de São Paulo, São Paulo, 1998.

FONSECA, Claudio D.; SEIXAS, Paulo Henrique D. Agenda nacional de Recursos Humanos em Saúde: diretrizes e prioridades. In: NEGRI, Barjas; FARIA, Regina; VIANA, Ana Luiza D. Recursos humanos em saúde: política, desenvolvimento e mercado de trabalho. Campinas: Universidade Estadual de Campinas, 2002. p. 289-322. 
KAMOCHE, Ken N. Understanding human resource management. Buckingham: Open University Press, 2001.

LA FORGIA, Gerard M.; COUTTOLENC, Bernard. Desempenho hospitalar no Brasil: em busca da excelência. São Paulo: Singular, 2009.

LENGNICK-HALL, Mark L. et al. Strategic human resource management: the evolution of the field. Human Resource Management Review, v. 19, n. 2, p. 64-85, 2009.

LOBATO, Lenaura V. Reorganizing the health care system in Brazil. In: FLEURY, Sonia; BELMARTINO Susana; BARIS, Enis. Resaping healthcare in Latin America: a comparative analysis of healthcare reform in Argentina, Brazil and Mexico. Ottawa: IRDC, 2000.

LONGO, Francisco. Mérito y flexibilidad. Barcelona: Ediciones Paidós Ibérica, 2004.

MAGALHÃES JÚNIOR, Helvécio M. Desafios e inovações na gestão do SUS em Belo Horizonte: a experiência de 2003 a 2008. Belo Horizonte: Mazza Edições, 2010.

ORGANIZAÇÃO MUNDIAL DA SAÚDE. Trabalhando juntos pela saúde. Relatório Mundial de Saúde 2006. Brasília: Ministério da Saúde, 2007.

PIERANTONI Célia; VARELLA Thereza C.; FRANÇA Tania. Recursos humanos e gestão do trabalho em saúde: da teoria para a prática. In: BARROS, André F. R. et al. (Org.). Observatório de recursos humanos em saúde no Brasil: estudos e análises. Brasília: Ministério da Saúde, 2004. v. 2, p. 51-70.

SARSUR, Amyra M. Empregabilidade e empresabilidade: um estudo junto a organizações e profissionais em Minas Gerais. Dissertação (mestrado em administração) — Faculdade de Ciências Econômicas, Universidade Federal de Minas Gerais, Belo Horizonte, 1999.

SEIXAS, Paulo Henrique D. Os pressupostos para a elaboração da política de recursos humanos nos sistemas nacionais de saúde. In: BRASIL, Ministério da Saúde. Política de Recursos Humanos em Saúde: seminário internacional. Brasília, 2002. p. 100-113.

SELTIZ, Claire et al. Métodos de pesquisa nas relações sociais. São Paulo: Herder, 1965.

YIN, Robert K. Estudo de caso: planejamento e métodos. Porto Alegre: Bookman, 2005.

Marina Campos Morici tem mestrado pelo Centro de Pós-Graduação e Pesquisa em Administração da Universidade Federal de Minas Gerais (Cedead/UFMG) e é professora do Centro Universitário de Belo Horizonte (UniBH). E-mail: marinamorici@gmail.com.

Allan Claudius Queiroz Barbosa tem pós-doutorado pelo Instituto Superior de Economia e Gestão da Universidade Técnica de Lisboa (Iseg/UTL) e é professor associado da UFMG. E-mail: allan@ufmg.br. 